\title{
KARAKTER PENDIDIK DALAM KITAB HADIS SAHIH AL-BUKHARI
}

\author{
Zulham Effendi (92212032641) \\ Alumni Program Studi Pendidikan Islam, Program Pascasarjana Universitas Islam \\ Negeri Sumatera Utara - Indonesia \\ zlhm.eff@gmail.com
}

\begin{abstract}
Abstrak: Tesis ini bertujuan untuk meneliti karakter pendidik dalam kitab hadis Sahih al-Bukhari. Penelitian ini perlu diadakan mengingat adanya sebagian pendidik pada hari ini, tidak dapat dijadikan sebagai tauladan yang baik oleh peserta didiknya, karena jauhnya mereka dari nilai dan akhlak islami yang terdapat dalam Alquran dan Hadis yang seharusnya dimiliki oleh pendidik. Hasil akhir dari penelitian ini adalah bahwa di dalam kitab hadis Sahih al-Bukhari terdapat karakter pendidik, yaitu: 1. Ikhlas karena Allah sebagaimana dalam hadis yang diriwayatkan oleh 'Umar ibn al-Khattab, 2. Takwa sebagaimana dalam hadis yang diriwayatkan oleh an-Nu'man ibn Basyir, 3. Berilmu sebagaimana dalam hadis yang diriwayatkan oleh 'Abdullah ibn 'Amr ibn al-'As, 4. Konsekuen, perkataan sesuai dengan perbuatan sebagaimana dalam hadis yang diriwayatkan oleh Usamah ibn Zaid ibn al-Hariśah, 5. Lemah lembut dan kasih sayang sebagaimana dalam hadis yang diriwayatkan oleh Anas ibn Malik, 6. Memperhatikan keadaan peserta didik sebagaimana dalam hadis yang diriwayatkan oleh Abu Wail dari 'Abdullah ibn Mas'ud, 7. Jujur dalam perkataan dan perbuatan sebagaimana dalam hadis yang diriwayatkan oleh Abu Hurairah, 8. Sabar sebagaimana dalam hadis yang diriwayatkan oleh Anas ibn Malik, 9. Tawadu' sebagaimana dalam hadis yang diriwayatkan oleh Anas ibn Malik, 10. Adil sebagaimana dalam hadis yang diriwayatkan oleh an-Nu'man ibn Basyir, 11. Bertanggung jawab sebagaimana dalam hadis yang diriwayatkan oleh 'Abdullah ibn 'Umar.
\end{abstract}

Kata Kunci: Karakter Pendidik, Kitab Hadis Sahih al-Bukhari

\section{Pendahuluan}

Pembahasan mengenai pendidik ideal merupakan pembahasan yang sangat penting untuk dikaji. Hal demikian disebabkan karena posisi pendidik dalam pengelolaan dan pengembangan pendidikan berada di barisan terdepan. Tanpa keberadaan pendidik, proses pendidikan tidak berarti apa-apa. Wajar kalau ada istilah yang menyebutkan, "الطريقة أهم من المادة ، ولكن المدرس أهم من الطريقة،" 
[Metode pembelajaran lebih penting dari materi. Akan tetapi, guru lebih penting lagi dari pada metode pembelajaran itu sendiri]. ${ }^{1}$

Secara bahasa pendidik adalah orang yang mendidik. ${ }^{2}$ Sedangkan di dalam UU Sisdiknas No. 20, Tahun 2003, dijelaskan bahwa pendidik adalah tenaga kependidikan yang berkualifikasi sebagai guru, dosen, konselor, pamong belajar, widyasuwara, tutor, instruktur, fasilisator, dan sebutan lain yang sesuai dengan kekhususannya, serta berpartisipasi dalam menyelenggarakan pendidikan. ${ }^{3}$

Nur Uhbiyati memberikan definisi tentang pendidik sebagai berikut:

Orang dewasa yang bertanggungjawab memberi bimbingan atau bantuan kepada anak didik dalam perkembangan jasmani dan rohaninya agar mencapai kedewasaannya, mampu melaksanakan tugasnya sebagai makhluk Allah, khalifah di permukaan bumi, sebagai makhluk sosial sebagai individu yang sanggup berdiri sendiri. ${ }^{4}$

Dalam Islam, pendidik yang ideal adalah Nabi Muhammad saw. karena beliau adalah Rasulullah saw., yaitu utusan Allah. Hal ini sebagaimana yang telah ditegaskan oleh Allah dalam Alquran surat al-Baqarah ayat 151:

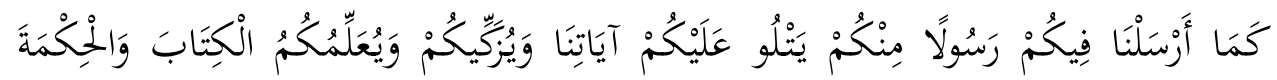

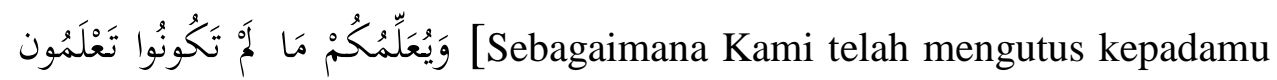
seorang Rasul (Muhammad) dari (kalangan) kamu yang membacakan ayat-ayat Kami, menyucikan kamu dan mengajarkan kepadamu kitab (Alquran) dan Hikmah (Sunnah), serta mengajarkan apa yang belum kamu ketahui]. ${ }^{5}$

Dan Rasulullah saw. juga menegaskan bahwa Allah mengutusnya kepada manusia sebagai pendidik. Hal ini sebagaimana yang terdapat dalam kitab hadis Sahih Muslim:

${ }^{1}$ Abdul Malik Fadjar, Holistika Pemikiran Pendidikan, edit. Ahmad Barizi, (Jakarta: RajaGrafindo Persada, 2005), h. 188.

2 Tim Penyusun Departemen Pendidikan Nasional, Kamus Besar Bahasa Indonesia (Jakarta: Gramedia Pustaka Utama, cet. 4, 2008), h. 326.

3 Undang-undang No. 20 Tahun 2003 tentang Sistem Pendidikan nasional, Bab I, Pasal 1 , poin 6 .

${ }^{4}$ Nur Uhbiyati, Ilmu Pendidikan Islam, (Bandung: Pustaka Setia, 1998), hal. 65.

${ }^{5}$ Departemen Agama RI, Al-Qur'an dan Terjamahnya, (Depok: PT Sabiq, 2009), h. 23. 


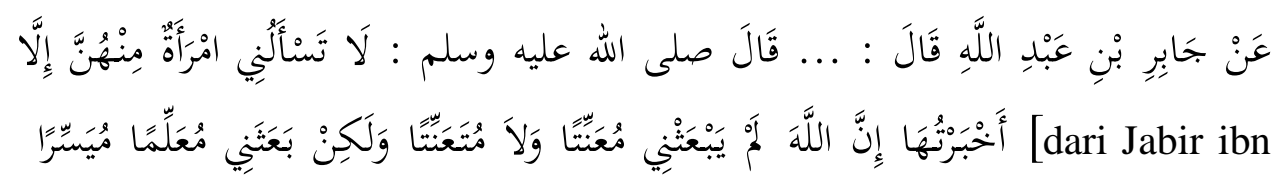

'Abdullah, dia berkata, ... Rasulullah saw. bersabda: "Tidaklah salah satu dari mereka bertanya kepadaku melainkan pasti aku mengabarinya. Sesungguhnya Allah tidak mengutusku untuk memaksa orang atau menjerumuskannya, akan tetapi Dia mengutusku sebagai seorang pendidik dan orang yang memudahkan urusan"]. ${ }^{6}$

Dan para sahabat Nabi juga menyatakan bahwa Nabi saw. adalah pendidik terbaik. Hal ini terdapat dalam hadis dalam kitab Sahih Muslim:

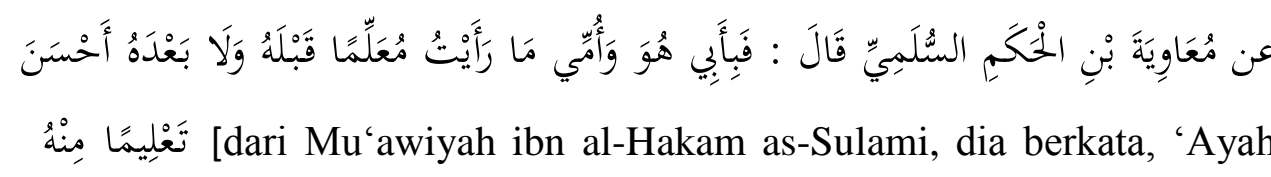
dan ibuku sebagai tebusanmu (ungkapan sumpah Arab), aku belum pernah bertemu seorang pendidik sebelum dan sesudahnya yang lebih baik pengajarannya daripada Rasulullah saw.]. ${ }^{7}$

Maka, untuk mewujudkan pendidik yang profesional dan ideal berdasarkan ruh Islam, tentu perlu melihat sisi kehidupan atau profil Rasulullah saw. sebagai pendidik ideal dan suri tauladan bagi umat islam, karena diantara tujuan utama diutusnya Rasulullah saw. ke permukaan bumi ini adalah sebagai uswah hasanah dan rahmat lil 'alamin. Semua hadis atau sunnah Rasulullah saw. menjadi panduan utama setelah Alquran bagi berbagai aspek kehidupan manusia terutama aspek pendidikan. Menurut Said Ismail Ali, sebagaimana yang dikutip oleh Hasan Langgulung, bahwa sumber pendidikan Islam terdiri atas enam macam, yaitu Alquran, hadis, perkataan sahabat, kemaslahatan umat (al-masalih al-mursalah), adat kebiasaan masyarakat ('urf), dan hasil pemikiran para ahli dalam Islam (ijtihad). Keenam sumber pendidikan Islam tersebut didudukkan secara hierarkis. Maksudnya ialah bahwa rujukan Islam diawali dari sumber pertama, yaitu Alquran, kemudian hadis, kemudian dilanjutkan pada sumber-

\footnotetext{
${ }^{6}$ Muslim, Sahih Muslim, tarqim wa tartib Muhammad Fuad 'Abd al-Baqi, (Kairo: Dar Ibn Hazm, 2010), no. 1478, h. 415.

${ }^{7}$ Ibid., no. 537, h. 144 .
} 
sumber berikutnya secara berurutan. ${ }^{8}$

Rasulullah saw. selain beliau sebagai seorang pendidik, beliau juga banyak menjelaskan dalam hadis-hadisnya tentang karakter pendidik. Seorang pendidik hendaknya mempelajari dan mengamalkan hadis-hadis tersebut sehingga menjadi sosok pendidik ideal yang islami.

Namun sangat disayangkan, sebagian besar pendidik hari ini, tidak lagi layak dijadikan sebagai teladan yang baik oleh anak-anak didiknya, karena jauhnya mereka dari nilai-nilai yang seharusnya dimiliki oleh seorang pendidik. Hal demikian bisa disebabkan oleh ketidaktahuan mereka terhadap profil Rasulullah saw. sebagai seorang pendidik dan hadis-hadis beliau yang menjelaskan tentang karakter pendidik.

Selanjutnya dominasi dunia Barat atas dunia Islam semakin besar hampir meliputi seluruh aspek kehidupan, terutama dalam aspek pendidikan. Di samping itu, banyak pemahaman yang keliru tentang keberadaan tugas dan tanggung jawab pendidik di tengah-tengah umat, terutama pendidik dalam pendidikan Islam. Banyak pendidik khususnya guru yang menganggap dirinya hanya sebagai pengajar di sekolah dalam wujud transfer pengetahuan, dan hanya sekedar hadir di sekolah untuk mengisi absen. Padahal, pendidik bukan saja bertugas untuk mentransfer dan mentransformasikan ilmu pengetahuan terhadap peserta didik, akan tetapi pendidik semestinya melaksanakan fungsi, tugas dan kedudukannya sebagai murabbi, mu'allim, muaddib, muzakki, mudarris, dan mursyid. Maka, mengkaji profil Rasulullah saw. sebagai pendidik ideal dan hadis-hadisnya merupakan saat yang tepat untuk menyusun kembali konsep-konsep bangunan pendidikan Islam, terutama komponen pendidik.

Akan tetapi, perlu diketahui bahwa tidak semua hadis Rasulullah saw. yang terdapat dalam kitab-kitab hadis yang ditulis oleh ulama hadis berderajat sahih. Hadis-hadis dalam kitab mereka ada yang sahih, hasan dan da'if. Namun, ada beberapa ulama hadis yang memang mengkhususkan penulisan hadis sahih

${ }^{8}$ Hasan Langgulung, Beberapa Pemikiran tentang Pendidikan Islam (Bandung: AlMa'arif, 1980), h. 35. 
dalam kitab hadisnya, di antaranya ialah al-Imam al-Bukhari yang menulis kitab al-Jami' as-Sahih atau yang lebih dikenal dengan Sahih al-Bukhari. Para ulama sepakat akan keabsahan kitab Sahih al-Bukhari bahkan menyatakan bahwa kitab tersebut merupakan kitab paling sahih derajatnya setelah Alquran. Hal ini sebagaimana yang disebutkan oleh an-Nawawi dalam Syarh Sahih Muslim:

$$
\begin{aligned}
& \text { اتفق العلماء رحمهم الله على أن أصح الكتب بعد القرآن العزيز الصحيحان البخاري } \\
& \text { Para Ulama - semoga Allah merahmati mereka } \\
& \text { - telah sepakat bahwa kitab yang paling Sahih setelah Alquran adalah } \\
& \text { kitab Sahih al-Bukhari dan Sahih Muslim, dan Umat ini telah menerima } \\
& \text { keabsahannya]. }{ }^{9}
\end{aligned}
$$

Oleh karena itu, seyogyanya dan sepantasnya setiap pendidik hendaknya membaca dan menelaah hadis-hadis sahih terutama tentang karakter pendidik sehingga dapat diamalkan dalam dunia pendidikan.

Berdasarkan uraian di atas, maka peneliti tertarik untuk mengangkat permasalahan ini dalam sebuah penelitian yang ilmiah yang berjudul "Karakter Pendidik Dalam Kitab Hadis Sahih al-Bukhari".

\section{Pembahasan}

\section{Pengertian Karakter Pendidik}

Menurut Kamus Besar Bahasa Indonesia karakter adalah sifat-sifat kejiwaan, akhlak atau budi pekerti yang membedakan seseorang dari yang lain. ${ }^{10}$

Adapun pendidik dalam Kamus Besar Bahasa Indonesia (KBBI) disebutkan bahwa pendidik adalah orang yang mendidik. ${ }^{11}$

Menurut Ahmad Tafsir, pendidik ialah, “orang-orang yang bertanggung jawab terhadap perkembangan anak didik dengan mengupayakan perkembangan seluruh potensi anak didik baik potensi afektif, potensi kognitif maupun potensi

\footnotetext{
${ }^{9}$ Yahya ibn Syarf an-Nawawi, al-Minhaj Syarh Sahih Muslim ibn al-Hajjaj, (Bairut: Dar Ihya' at-Turaś al-'Arabi, cet. 2, 1392 H), jilid I, h. 14

${ }^{10}$ Tim Penyusun Departemen Pendidikan Nasional, Kamus Besar ..., h. 623.

${ }^{11}$ Ibid., h. 326.
} 
psikomotorik sesuai dengan nilai-nilai ajaran Islam."

Adapun menurut Zakiah Daradjat bahwa pendidik itu ialah individu yang memberikan kebutuhan ilmu pengetahuan, sikap dan tingkah laku peserta didik. ${ }^{13}$

Adapun karakter pendidik, menurut al-Abrasyi dalam Ahmad Tafsir, bahwa seorang pendidik seharusnya memiliki karakter sebagai berikut:

1. Ikhlas sepenuh hati dalam melaksanakan tugasnya

2. Zuhud, yaitu tidak mengutamakan materi dunia, mengajar dilakukan karena mengharapkan keridhaan Allah semata.

3. Bersih jasmaninya, yaitu penampilan lahiriyahnya harus menyenangkan.

4. Bersih jiwanya, yaitu menjauhi dosa-dosa besar.

5. Tidak riya karena riya akan menghilangkan keikhlasan.

6. Tidak memendam rasa dengki, iri hati dan tidak menyukai permusuhan.

7. Perkataan dan perbuatannya sesuai.

8. Tidak malu untuk mengatakan, 'saya tidak tahu'. Bijaksana.

9. Rendah hati dan lemah lembut.

10. Sabar, tidak marah karena hal-hal kecil.

11. Pemaaf, seorang pendidik harus bersifat pemaaf terhadap peserta didik. Dia sanggup menahan diri, menahan amarah, lapang hati, banyak bersabar dan tidak marah karena sebab-sebab yang kecil.

12. Tegas dalam perkataan dan perbuatan, tetapi tidak kasar.

13. Tidak merasa rendah diri dan berkepribadian.

14. Bersifat kebapaan, mencintai murid seperti mencintai anaknya sendiri. ${ }^{14}$ Menurut Mahmud Junus dalam Ahmad Tafsir juga, bahwa seorang pendidik hendaklah memiliki karakter sebagai berikut:

1. Kasih sayang pada murid dan senang memberi nasehat.

12 Ahmad Tafsir, Ilmu Pendidikan dalam Perspektif Islam, (Bandung: PT Remaja Rosdakarya, 1992), h. 74.

${ }^{13}$ Zakiah Daradjat, Islam Untuk Disiplin Ilmu Pendidikan, (Jakarta: Bulan Ibntang, 1987), h. 19 .

14 Ahmad Tafsir, Ilmu Pendidikan Islam, (Bandung: PT Remaja Rosdakarya, cet. 2, 2013), h. 131. 
2. Senang melarang dan mencegah murid dari melakukan perbuatan tercela.

3. Bijak dalam memilih bahan pelajaran yang sesuai dengan murid.

4. Hormat pada pelajaran lain yang bukan pegangannya.

5. Bijak dalam memilih bahan pelajaran yang sesuai dengan kemampuan dan kecerdasan murid.

6. Jujur dalam keilmuan dan adil. ${ }^{15}$

\section{Kitab Hadis Sahih al-Bukhari}

Kitab hadis Sahih al-Bukhari adalah kitab al-Jami ‘ as-Sahih yang disusun oleh Muhammad ibn Ismail al-Bukhari. Adapun sebab al-Bukhari menyusun kitab Sahih al-Bukhari adalah sebagaimana yang beliau kisahkan. Al-Bukhari berkata, "Pada suatu hari aku bersama Ishaq ibn Rahawaih. Maka berkata sebagian orang yang hadir waktu itu, 'Seandainya saja kalian menyusun sebuah kitab yang ringkas untuk hadis-hadis Nabi saw. '. Ternyata hal itu sangat membekas di hatiku, mulailah aku menyusun kitab ini (Sahih al-Bukhari)."16

Dalam menulis kitab al-Jami` as-Sahih, al-Bukhari menggunakan kaidah penelitian secara ilmiah dan cukup modern sehingga hadis-hadisnya dapat dipertanggung-jawabkan. Dengan bersungguh-sungguh ia meneliti dan menyelidiki kredibilitas para perawi sehingga benar-benar memperoleh kepastian akan kesahihan hadis yang diriwayatkan. Ia juga selalu membandingkan hadis satu dengan yang lainnya, memilih dan menyaring, mana yang menurut pertimbangannya secara nalar paling sahih. Dengan demikian, kitab hadis susunan al-Bukhari benar-benar menjadi batu uji dan penyaring bagi sejumlah hadis lainnya. Hal ini sebagaimana yang dikatakan oleh al-Bukhari, "Saya tidak mencantumkan satu hadis pun dalam kitab ini kecuali hadis-hadis yang sahih"17

Isi kitab Sahih al-Bukhari terdiri dari 97 kitab (bagian) dan lebih dari 3.400 bab, dimulai dari pembahasan tentang wahyu dan ditutup dengan

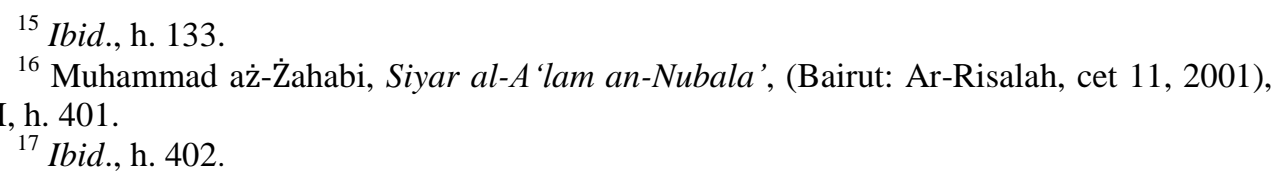

${ }^{16}$ Muhammad aż-Żahabi, Siyar al-A 'lam an-Nubala', (Bairut: Ar-Risalah, cet 11, 2001),

${ }^{17}$ Ibid., h. 402. jilid XII, h. 401. 
pembahasan tentang tauhid. Al-Bukhari dalam menyusun kitabnya ini, beliau menggunakan susunan dan topik pembahasan yang biasanya digunakan dalam ilmu fikih. Hadis-hadis yang akan ditulis itu dipilih dan dikelompokkan berdasarkan bidang-bidang yang menjelaskan bagian-bagian yang ada, dengan menyebutkan sanad hadis-hadis tersebut secara lengkap.

\section{Karakter Pendidik dalam Kitab Hadis Sahih al-Bukhari}

\section{Ikhlas Karena Allah}

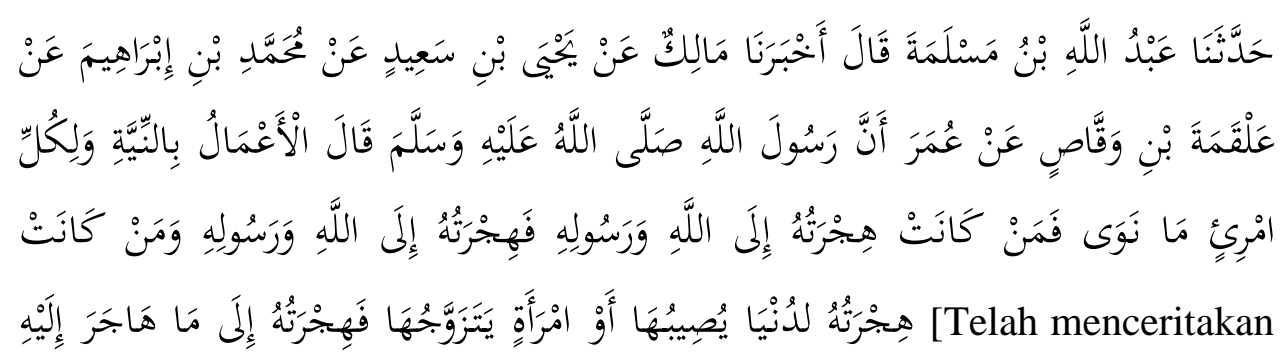
kepada kami 'Abdullah ibn Maslamah, dia berkata, telah mengabarkan kepada kami Malik, dari Yahya ibn Sa'id, dari Muhammad ibn Ibrahim, dari 'Alqamah ibn Waqqas, dari 'Umar, bahwa Rasulullah saw. bersabda: "Semua perbuatan tergantung niatnya, dan (balasan) bagi tiap-tiap orang tergantung apa yang diniatkan. Barangsiapa niat hijrahnya karena Allah dan Rasul-Nya, maka hijrahnya adalah kepada Allah dan Rasul-Nya. Barangsiapa niat hijrahnya karena dunia yang ingin digapainya atau karena seorang perempuan yang ingin dinikahinya, maka hijrahnya adalah kepada apa yang dia diniatkan.”]. ${ }^{18}$

Ikhlas merupakan syarat diterimanya suatu amalan. Allah tidak akan menerima ibadah apa pun dari hamba-Nya kecuali hamba itu melakukannnya dengan ikhlas, hanya mengharapkan ridha-Nya. Dalam Alquran, surat al-

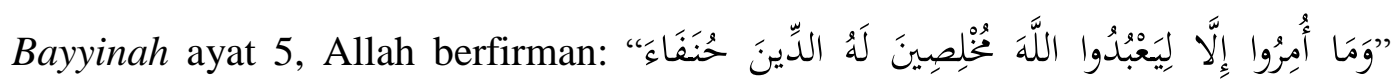
[padahal mereka hanya diperintahkan menyembah Allah dengan ikhlas menaatiNya semata-mata karena (menjalankan) agama]. ${ }^{19}$

${ }^{18}$ Muhammad ibn Isma'il al-Bukhari, Sahih al-Bukhari, tarqim wa tartib Muhammad Fuad 'Abd al-Baqi, (Kairo: Dar Ibn Hazm, 2010), no. 54, h. 16.

${ }^{19}$ Departemen Agama, Al-Qur'an dan Terjemahnya, h. 598. 
Seorang pendidik hendaklah ikhlas dalam mendidik karena mendidik dalam Islam merupakan ibadah, dan ibadah harus dilakukan dengan ikhlas karena Allah. Bahkan, jika dia tidak ikhlas dalam mendidik, ingin mendapatkan pujian, riya' dan sum'ah atau karena ingin mendapatkan kepentingan dunia, dia bisa termasuk di antara golongan pertama yang akan dimasukkan ke dalam api neraka sebagaimana dalam hadis yang terdapat dalam Sahih Muslim.

\section{Takwa}

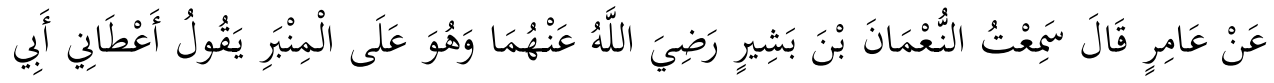

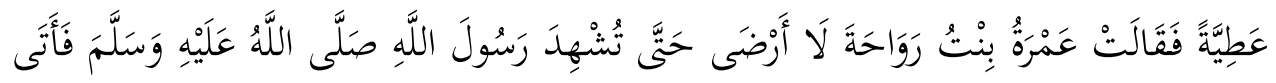

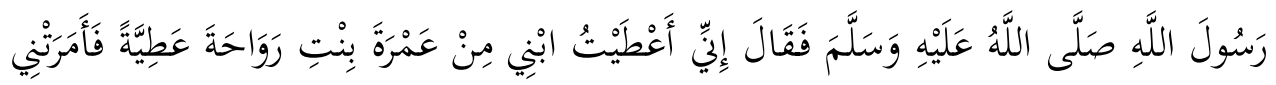

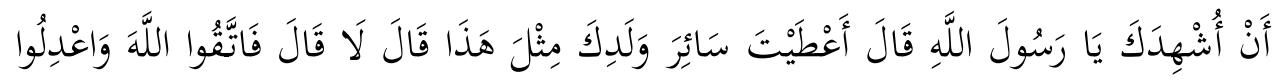

[Dari 'Amir berkata, aku mendengar an-Nu'man ibn Basyir berkhutbah di atas mimbar, dia berkata, 'Bapakku memberiku sebuah hadiah (pemberian tanpa imbalan). Maka 'Amrah putri Rawahah berkata, 'Aku tidak rela sampai kamu mempersaksikannya kepada Rasulullah saw..' Maka bapakku menemui Rasulullah saw. dan berkata, 'Aku memberi anakku sebuah hadiah yang berasal dari 'Amrah putri Rawahah, namun dia memerintahkan aku agar aku mempersaksikannya kepada anda, wahai Rasulullah". Rasulullah saw. bertanya: "Apakah semua anakmu kamu beri hadiah seperti ini?”. Dia menjawab: Tidak. Rasulullah saw. bersabda: "Bertakwalah kalian kepada Allah dan berbuat adillah antara anak-anak kalian"..]. ${ }^{20}$

Dalam hadis di atas Rasulullah saw. memerintahkan kepada seorang ayah yang merupakan pendidik pertama bagi anak-anaknya agar bertakwa kepada Allah karena dengan taqwa seorang ayah dapat berlaku adil di antara anak-anaknya dan menjadi suri teladan yang baik bagi mereka.

\section{Berilmu}

عَنْ عَبْدِ اللَّهِ بْنِ عَمْرِو بْنِ الْعَاصِ قَالَ سَمَعْتُ رَسُولَ اللَّهِ صَلَّى اللَّهُ عَلَيْهِهِ وَسَلَّمَ يَقُولُ إِنَّ

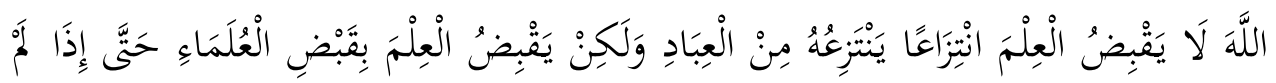

\footnotetext{
${ }^{20}$ Al-Bukhari, Sahih al-Bukhari, no. 2587, h. 308.
} 
[Dari

'Abdullah ibn 'Amr ibn al-'As, dia berkata, 'aku mendengar Rasulullah saw. bersabda: "Sesungguhnya Allah tidaklah mencabut ilmu sekaligus mencabutnya dari hamba-hamba-Nya, akan tetapi Allah mencabut ilmu dengan cara mewafatkan para ulama hingga bila sudah tidak tersisa ulama maka manusia akan mengangkat pemimpin dari kalangan orang-orang bodoh, ketika mereka ditanya mereka berfatwa tanpa ilmu, mereka sesat dan menyesatkan."]. ${ }^{21}$

Dari hadis di atas dapat dipahami bahwa orang yang berfatwa dan mengajar harus memiliki ilmu. Termasuk dalam hal ini ialah pendidik, pendidik haruslah orang yang berilmu. Jika seorang pendidik tidak berilmu tentu peserta didik yang diajarnya akan sesat. Ibnu Hajar al-'Asqalani menjelaskan bahwa makna hadis ini adalah bahwa Nabi saw. mencela orang yang berfatwa dengan kebodohan. Maka, Nabi saw. mensifati mereka dengan sesat dan menyesatkan]. ${ }^{22}$

\section{Konsekuen, Perkataan Sesuai dengan Perbuatan}

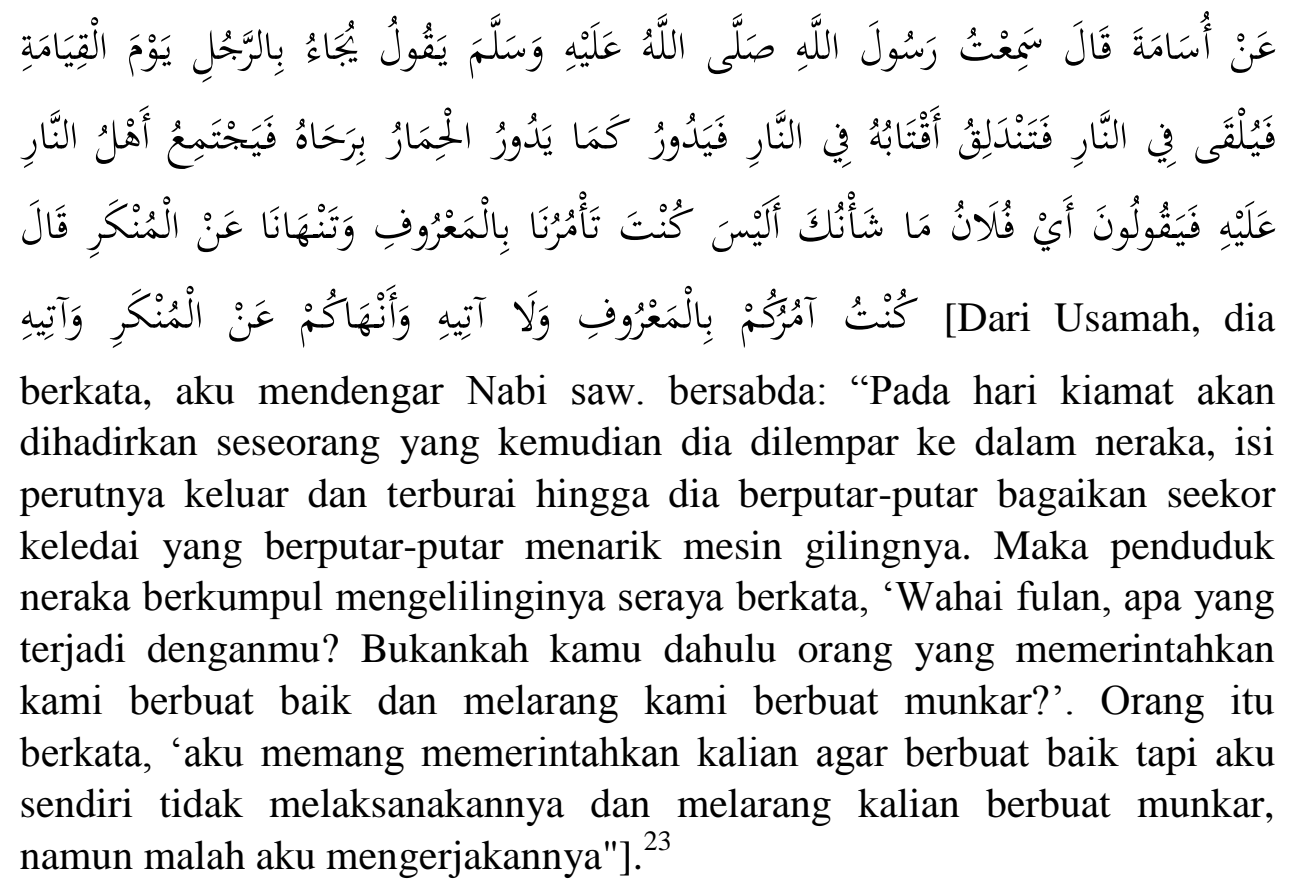
berkata, aku mendengar Nabi saw. bersabda: "Pada hari kiamat akan dihadirkan seseorang yang kemudian dia dilempar ke dalam neraka, isi perutnya keluar dan terburai hingga dia berputar-putar bagaikan seekor keledai yang berputar-putar menarik mesin gilingnya. Maka penduduk neraka berkumpul mengelilinginya seraya berkata, 'Wahai fulan, apa yang terjadi denganmu? Bukankah kamu dahulu orang yang memerintahkan kami berbuat baik dan melarang kami berbuat munkar?'. Orang itu berkata, 'aku memang memerintahkan kalian agar berbuat baik tapi aku sendiri tidak melaksanakannya dan melarang kalian berbuat munkar, namun malah aku mengerjakannya"]. ${ }^{23}$

\footnotetext{
${ }^{21}$ Al-Bukhari, Sahih al-Bukhari, no. 100, h. 23.

${ }^{22}$ Ahmad ibn Ali ibn Hajar al-'Asqalani, Fath al-Bari Syarh Sahih al-Bukhari, (Bairut: Dar al-Ma'rifah, 1379 H), jilid XIII, h. 285.

${ }^{23}$ Al-Bukhari, Sahih al-Bukhari, no. 3267, h. 395.
} 
Hadis di atas menjelaskan tentang orang yang hanya mengajak orang lain mengerjakan kebaikan, tapi dia sendiri tidak mengerjakannya. Dan melarang mereka dari melakukan perbuatan buruk, tapi dia sendiri melakukannya. Maka, Allah mencampakkannya ke dalam neraka karena ucapannya tidak sesuai dengan perbuatannya. Mengajak kepada kebaikan dan melarang dari kejahatan adalah salah satu tugas yang dikerjakan oleh pendidik. Jadi, pendidik harus mengamalkan ilmu yang diajarkannya kepada peserta didik dan hendaklah perkataannya sesuai dengan perbuatannya agar terhindar dari siksaan Allah.

Pendidik adalah orang yang paling membutuhkan keselarasan antara perkataan dan perbuatannya, dia adalah contoh yang diteladani. Para anak didiknya mengambil akhlak, adab dan ilmu darinya.

Asy-Syulhub menjelaskan tentang pentingnya konsekuen bagi pendidik:

Maka, wajib atas para pendidik dan pengajar agar selalu takut kepada Allah, karena para anak didik tersebut adalah amanat yang dipikulkan dipundak mereka. Hendaklah mereka berjuang keras dalam mengajarkan apa yang bermanfaat bagi anak didik serta menserasikan antara ucapan dengan tindakan nyata mereka, karena hal itu akan memperkokoh ilmu yang mereka ajarkan. ${ }^{24}$

\section{Lembah Lembut dan Kasih Sayang}

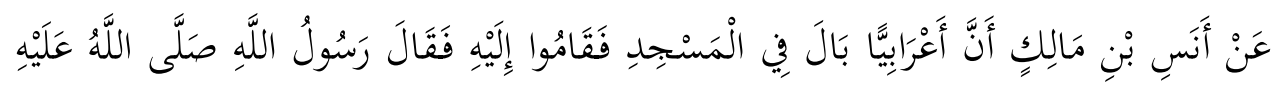
[Dari Anas ibn Malik bahwa seorang arab badui kencing di masjid, lalu orang-orang mendatanginya, maka Rasulullah saw. bersabda: "Biarkanlah dia". Kemudian Rasulullah saw. meminta diambilkan air lalu air itu disiramkan di atasnya]. ${ }^{25}$

Hadis di atas menjelaskan bagaimana kelembutan dan kasih sayang Rasulullah saw. kepada umatnya yang merupakan peserta didiknya. Seorang arab badui melakukan perbuatan yang sangat tidak baik, yaitu buang air kecil di masjid, rumah Allah, tempat beribadah umat Islam. Para sahabat yang melihat kejadian tersebut marah dan hendak menghentikannya. Tapi, Rasulullah saw.

\footnotetext{
${ }^{24}$ Fuad asy-Syulhub, Begini Seharusnya Menjadi Guru, terj. Jamaluddin, (Jakarta: Darul Haq, cet. 8, 2015), h. 14 .

${ }^{25}$ Al-Bukhari, Sahih al-Bukhari, no. 6025, h. 730.
} 
tidak marah dan memerintahkan para sahabatnya untuk membiarkannya hingga selesai. Kemudian, Rasulullah saw. menasehati dan mendidiknya .

Ibnu Battal menjelaskan bahwa hadis ini menunjukkan atas penggunaan sikap lemah lembut kepada orang yang tidak tahu -berbeda dengan orang yang sudah tahu- dan meninggalkan celaan serta cacian terhadapnya]. ${ }^{26}$

\section{Memperhatikan Keadaan Peserta Didik}

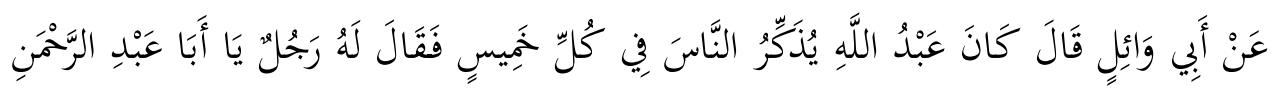

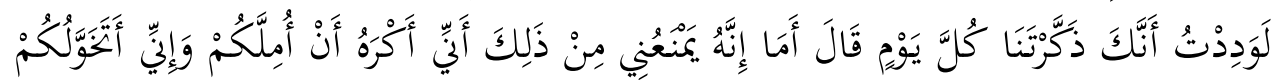

$$
\begin{aligned}
& \text { [Dari }
\end{aligned}
$$

Abu Wail, dia berkata, 'bahwa 'Abdullah (Ibnu Mas'ud) memberi pelajaran kepada orang-orang setiap hari Kamis, kemudian seseorang berkata, 'Wahai Abu 'Abd ar-Rahman, sungguh aku ingin kalau anda memberi pelajaran kepada kami setiap hari'. Dia berkata: "Sungguh aku enggan melakukannya, karena aku takut membuat kalian bosan, dan aku ingin memberi pelajaran kepada kalian sebagaimana Nabi saw. memberi pelajaran kepada kami karena khawatir kebosanan akan menimpa kami"..]. ${ }^{27}$

Hadis di atas memberikan informasi bahwa Nabi saw. tidak mengajar para sahabatnya setiap hari, tetapi ada waktu belajar dan ada waktu istirahat. Hal itu dilakukan oleh Nabi saw. untuk menghindari kebosanan peserta didik terhadap pelajaran. Hal ini menunjukkan bahwa Nabi saw. memperhatikan kondisi para sahabat yang merupakan peserta didiknya dalam belajar.

\section{Jujur dalam Perkataan dan Perbuatan}

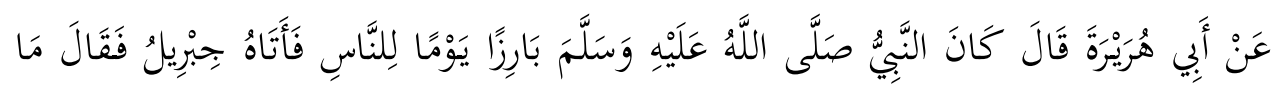
[Dari Abu

Hurairah, dia berkata, bahwa Nabi saw. pada suatu hari menemui para sahabat, lalu datang Malaikat Jibril yang kemudian bertanya: "Apakah itu iman?" ....... Jibril bertanya kembali: "Kapan terjadinya hari kiamat?" Nabi saw. menjawab: "Yang ditanya tentang itu tidak lebih tahu dari yang bertanya"]. ${ }^{28}$

26 'Ali ibn Khalf ibn Battal, Syarh al-Bukhari, tahqiq Abu Tamim Yasir ibn Ibrahim, (Riyad: Maktabah ar-Rusyd, cet. 2, 2003), jilid IX, h. 225.

${ }^{27}$ Al-Bukhari, Sahih al-Bukhari, no. 70, h. 19.

${ }^{28}$ Al-Bukhari, Sahih al-Bukhari, no. 50, h. 15. 
Dalam hadis di atas disebutkan bahwa ketika Nabi saw. ditanya oleh Malaikat Jibril tentang hari kiamat, Nabi saw. menjawab, "Saya tidak lebih tahu daripada anda". Nabi saw. meskipun seorang Rasulullah, yaitu utusan Allah, namun Nabi saw. tidak segan dan tidak malu untuk mengatakan tidak tahu jika ditanya suatu masalah yang Nabi saw. tidak mengetahui jawabannya. Hal ini menunjukkan bahwa seorang pendidik harus bersifat jujur kepada peserta didiknya. Apabila dia ditanya suatu hal yang tidak diketahuinya, dia harus berani mengatakan tidak tahu dan jangan mengada-ada untuk menjaga gengsinya.

Menurut Muhammad 'Ali al-Bakri bahwa dalam hadis ini terdapat pelajaran yaitu apabila seorang mufti (termasuk pendidik) ditanya tentang sesuatu yang tidak diketahuinya hendaknya (dia jujur) mengatakan, 'saya tidak tahu']. ${ }^{29}$

\section{Sabar}

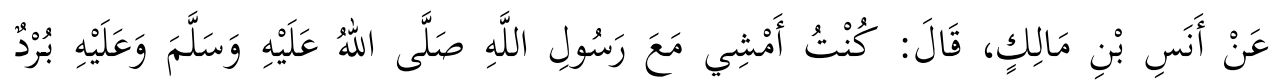

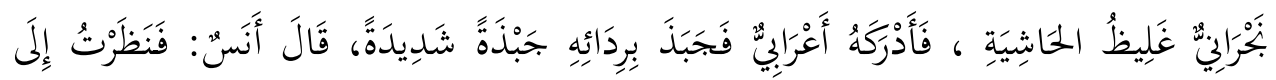

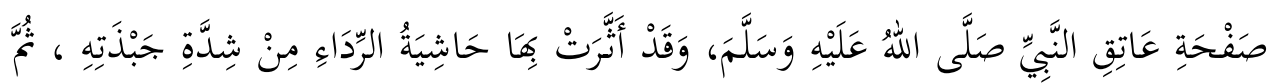

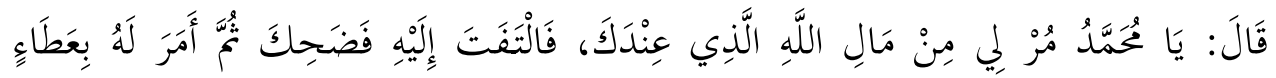

[Dari Anas ibn Malik, 'Aku pernah berjalan bersama Nabi saw. yang ketika itu Nabi saw. mengenakan selendang yang tebal dan kasar buatan Najran. Kemudian seorang arab badui datang lalu menarik Nabi saw. dengan tarikan yang keras hingga aku melihat permukaan pundak Nabi saw. berbekas akibat tarikan yang keras itu. Lalu dia berkata kepada Nabi saw. berkata, 'Perintahkanlah, agar aku diberikan harta Allah yang ada padamu'. Kemudian Nabi saw. memandang kepada orang arab badui itu dan tertawa. Lalu Nabi saw. memerintahkan agar memberinya]. ${ }^{30}$

Hadis di atas menjelaskan bagaimana kesabaran Rasulullah saw. terhadap kelakuan buruk arab badui kepadanya. Al-Muhallab dalam Ibnu Battal bahwa dalam hadis orang yang menarik Nabi saw. mengandung makna yang telah disebutkan yaitu kesabaran pemimpin dan ulama terhadap orang-orang bodoh,

\footnotetext{
${ }^{29}$ Muhammad 'Ali al-Bakri, Dalil al-Falihin li Turuq Riyad as-Salihin, (Bairut: Dar alMa'rifah, 2004), jilid I, h. 226.

${ }^{30}$ Al-Bukhari, Sahih al-Bukhari, no. 6088, h. 736.
} 
menggunakan sikap lemah lembut kepada mereka dan sabar atas gangguan mereka dalam harta dan jiwa]. ${ }^{31}$

Seorang pendidik hendaklah memiliki sifat sabar dan menahan emosinya dalam menjalankan tugasnya sebagai pendidik karena dia pasti akan mendapati berbagai macam perkara yang tidak dia sukai dari peserta didiknya.

Menurut Fuad asy-Syulhub bahwa kaitan sabar dengan pendidikan, ialah pendidik khususnya guru akan berkomunikasi dengan individu-individu yang memiliki watak dan pemahaman yang berbeda-beda. Di antara mereka ada yang bagus dan ada yang lemah. Di samping kesibukan guru dengan tugas memeriksa dan mengajar yang dilakukan terus-menerus setiap hari pada waktu jam belajar, ditambah dengan berbagai permasalahan siswa yang sering terjadi. Maka, hal ini menuntut guru untuk dapat bersabar dalam menghadapinya. Hilang kesabaran dan melampiaskan emosi bisa menjerumuskan guru pada kesulitan besar, terutama jika hal itu terjadi pada waktu aktivitas belajar mengajar sedang berlangsung. ${ }^{32}$

\section{Tawadu'}

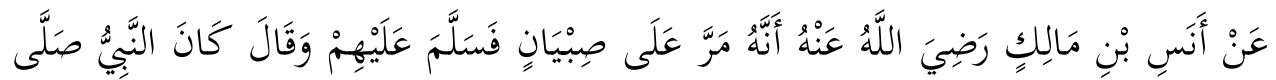
[Dari Anas ibn Malik, bahwa dia pernah melewati anakanak kecil, lalu dia memberi salam kepada mereka dan berkata, 'Nabi saw. juga biasa melakukan hal ini.']. ${ }^{33}$

Hadis di atas meriwayatkan bahwa Nabi saw. sering mengucapkan salam kepada anak-anak. Perbuatan Nabi saw. ini ditiru oleh sahabatnya sekaligus pembantunya, yaitu Anas ibn Malik. Hal ini menunjukkan atas ketawadhuan Nabi saw., Nabi saw. tidak pernah menganggap remeh orang lain meskipun mereka adalah anak-anak. Ibnu Battal menjelaskan bahwa ucapan salam Nabi saw. kepada anak-anak merupakan bagian dari akhlaknya yang agung, dan adabnya yang mulia serta bagian dari ketawadhuannya saw.]. ${ }^{34}$

Rasulullah saw. yang merupakan guru besar dan pendidik nomor satu umat ini selalu bersikap tawadu' dan tidak sombong. Maka, hendaklah seorang

\footnotetext{
${ }^{31}$ Ibnu Battal, Syarh Sahih al-Bukhari, jilid V, h. 318.

${ }^{32}$ Fuad asy-Syulhub, Begini Seharusnya Menjadi Guru,h. 40-41.

${ }^{33}$ Al-Bukhari, Sahih al-Bukhari, no. 6247, h. 753.

${ }^{34}$ Ibnu Battal, Syarh Sahih al-Bukhari, jilid IX, h. 27.
} 
pendidik selalu bersikap tawadu' karena tawadu' adalah sifat yang terpuji dan salah satu sebab dalam menghilangkan adanya jarak antara pendidik dan anak didiknya. Dan hendaklah seorang pendidik menjauhi sifat sombong dan ujub karena itu merupakan sifat yang tercela dan akan menyebabkan anak didiknya menjauh darinya serta berpaling dari menimba ilmu darinya.

10. Adil

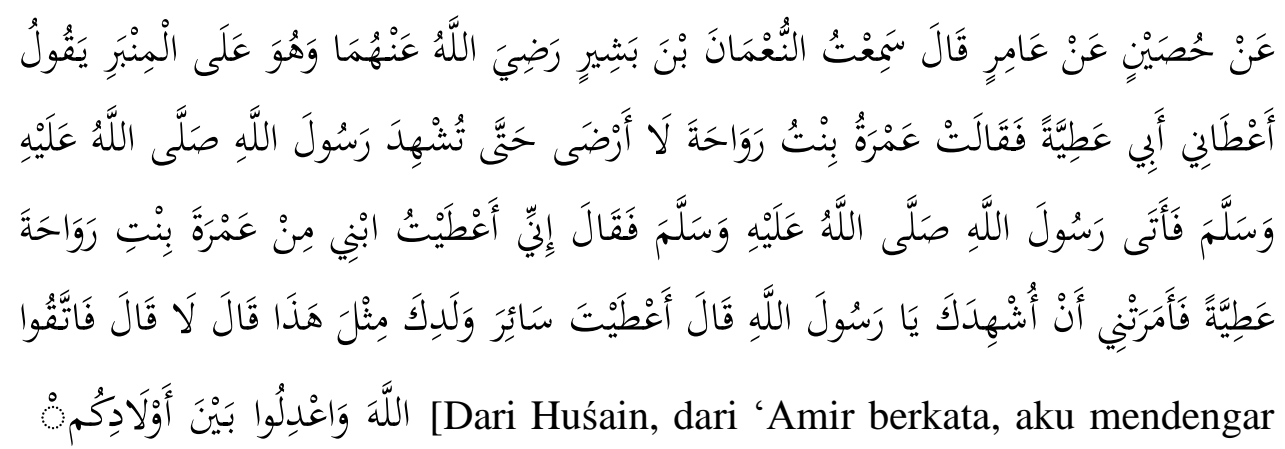
an-Nu'man ibn Basyir berkhutbah diatas mimbar, dia berkata, 'Bapakku memberiku sebuah hadiah (pemberian tanpa imbalan). Maka 'Amrah putri Rawahah berkata, 'Aku tidak rela sampai kamu mempersaksikannya kepada Rasulullah saw..' Maka bapakku menemui Rasulullah saw. dan berkata, 'Aku memberi anakku sebuah hadiah yang berasal dari 'Amrah putri Rawahah, namun dia memerintahkan aku agar aku mempersaksikannya kepada anda, wahai Rasulullah". Rasulullah saw. bertanya: "Apakah semua anakmu kamu beri hadiah seperti ini?". Dia menjawab: Tidak. Beliau bersabda: "Bertakwalah kalian kepada Allah dan berbuat adillah antara anak-anak kalian".]. ${ }^{35}$

Hadis di atas sangat menekankan kepada para orang tua agar berlaku adil kepada anak-anak mereka karena orang tua merupakan pendidik pertama bagi anak. Dan di dalam konteks pendidikan, pendidik adalah orang tua bagi peserta didik. Dengan demikian, pendidik juga wajib berlaku adil dalam berbagai hal terhadap peserta didiknya. Karena, berlaku tidak adil antara mereka akan menimbulkan permusuhan dan saling membenci antara mereka. Hamzah Muhammad Qasim berkata bahwa di dalam hadis ini terdapat dalil haramnya berlaku tidak adil dan mengutamakan sebagian mereka (anak-anak) atas sebagian

\footnotetext{
${ }^{35}$ Al-Bukhari, Sahih al-Bukhari, no. 2587, h. 308.
} 
yang lain dapat menimbulkan permusuhan, saling membenci dan pemutusan tali silaturahmi di antara mereka. ${ }^{36}$

\section{Bertanggung Jawab}

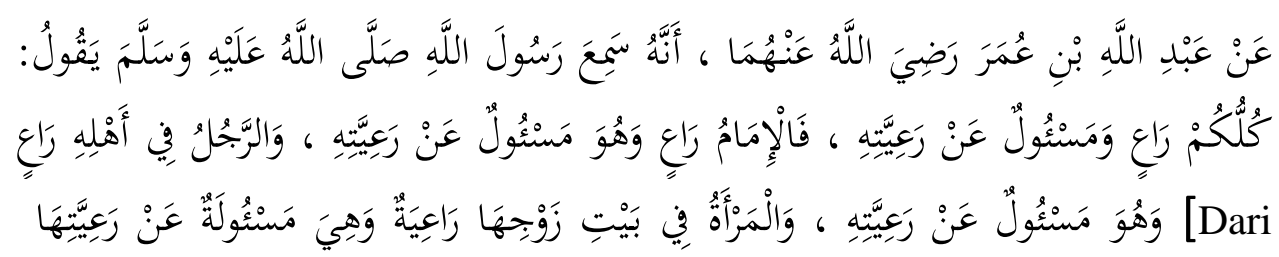

'Abdullah ibn 'Umar, bahwa dia mendengar Rasulullah saw. bersabda: "Setiap kalian adalah pemimpin dan setiap pemimpin akan diminta pertanggung jawaban atas yang dipimpinnya. Imam (kepala Negara) adalah pemimpin yang akan diminta pertanggung jawaban atas rakyatnya. Seorang suami dalam keluarganya adalah pemimpin dan akan diminta pertanggung jawaban atas keluarganya. Seorang isteri adalah pemimpin di dalam urusan rumah tangga suaminya dan akan diminta pertanggung jawaban atas urusan rumah tangga tersebut."]. ${ }^{37}$

Hadis di atas menjelaskan bahwa setiap orang adalah pemimpin, setiap pemimpin akan diminta pertanggung jawaban atas yang dipimpinnya. Kepala rumah tangga adalah pemimpin bagi istri dan anak-anaknya, dan dia akan diminta pertanggung jawaban atas mereka. Maka, seorang kepala rumah tangga berkewajiban memenuhi hak istri dan anak-anaknya, dan termasuk hak mereka adalah mendidik dan mengajari mereka apa-apa yang bermanfaat dan yang tidak bermanfaat bagi mereka. Ibnu Battal menyebutkan dalam kitabnya, Syarh Sahih al-Bukhari tentang penjelasan hadis di atas bahwa seorang laki-laki bertanggung jawab atas keluarganya. Jika demikian, maka wajib atasnya mendidik dan mengajarkan kepada mereka yang dapat menjaga mereka dari api neraka]. ${ }^{38}$

Selalu merasa bertanggung jawab akan membuat seseorang melaksanakan tugasnya dengan baik. Karena, dia menyadari bahwa dia akan diminta pertanggungjawaban atas tugas-tugasnya tersebut. Begitu juga seharusnya seorang pendidik, hendaknya selalu merasa bertanggung jawab atas anak didiknya. Hal demikian, sangat membantunya dalam melaksanakan tugasnya sebagai seorang

${ }^{36}$ Hamzah Muhammad Qasim, Manar al-Qari Syarh Mukhtasar Sahih al-Bukhari, muraja'ah 'Abd al-Qadir al-Arna'ut, (Damaskus: Maktabah Dar al-Bayan, 1990), jilid IV, h. 14.

${ }^{37}$ Al-Bukhari, Sahih al-Bukhari, no. 5188, h. 644.

${ }^{38}$ Ibnu Battal, Syarh Sahih al-Bukhari, jilid VII, h. 296. 
pendidik dengan sebaik-baiknya. Apabila sifat ini hilang dari seorang pendidik, maka dia akan menyepelekan hak-hak anak didiknya berupa pengajaran dan perhatian serta penyucian jiwa dan akhlak mereka.

\section{Kesimpulan}

Berdasarkan penjelasan dan uraian pada pembahasan-pembahasan sebelumnya, maka dapat ditarik kesimpulan akhir dan penutup pada penelitian ini bahwa dalam kitab hadis Sahih al-Bukhari terdapat karakter pendidik, yaitu:

a. Ikhlas karena Allah, hal ini sebagaimana yang terdapat dalam hadis yang diriwayatkan oleh 'Umar ibn al-Khattab.

b. Takwa, hal ini sebagaimana yang terdapat dalam hadis yang diriwayatkan oleh an-Nu'man ibn Basyir.

c. Berilmu, hal ini sebagaimana yang terdapat dalam hadis yang diriwayatkan oleh 'Abdullah ibn 'Amr ibn al-'As.

d. Konsekuen, perkataan sesuai dengan perbuatan, hal ini sebagaimana yang terdapat dalam hadis yang diriwayatkan oleh Usamah ibn Zaid ibn al-Hariśah.

e. Lemah lembut dan kasih sayang, hal ini sebagaimana yang terdapat dalam hadis yang diriwayatkan oleh Anas ibn Malik.

f. Memperhatikan keadaan peserta didik, hal ini sebagaimana yang terdapat dalam hadis yang diriwayatkan oleh Abu Wail dari 'Abdullah ibn Mas`ud.

g. Jujur dalam perkataan dan perbuatan, hal ini sebagaimana yang terdapat dalam hadis yang diriwayatkan oleh Abu Hurairah.

h. Sabar, hal ini sebagaimana yang terdapat dalam hadis yang diriwayatkan oleh Anas ibn Malik.

i. Tawadu',hal ini sebagaimana yang terdapat dalam hadis yang diriwayatkan oleh Anas ibn Malik.

j. Adil, hal ini sebagaimana yang terdapat dalam hadis yang diriwayatkan oleh an-Nu'man ibn Basyir.

k. Bertanggung jawab, hal ini sebagaimana yang terdapat dalam hadis yang diriwayatkan oleh 'Abdullah ibn 'Umar. 


\section{Pustaka Acuan}

Al-'Asqalani, Ahmad ibn Ali ibn Hajar. Fath al-Bari Syarh Sahih al-Bukhari,. Bairut: Dar al-Ma'rifah, $1379 \mathrm{H}$.

Al-Bakri, Muhammad 'Ali. Dalil al-Falihin li Turuq Riyad as-Salihin. Bairut: Dar al-Ma'rifah, 2004.

Al-Bukhari, Muhammad ibn Isma'il. Sahih al-Bukhari, tarqim wa tartib Muhammad Fuad 'Abd al-Baqi. Kairo: Dar Ibn Hazm, 2010.

An-Nawawi, Yahya ibn Syarf. al-Minhaj Syarh Sahih Muslim ibn al-Hajjaj. Bairut: Dar Ihya' at-Turaś al-'Arabi, cet. 2, 1392 H.

Asy-Syulhub, Fuad. Begini Seharusnya Menjadi Guru, terj. Jamaluddin. Jakarta: Darul Haq, cet. 8, 2015.

Aż-Żahabi, Muhammad. Siyar al-A 'lam an-Nubala'. Bairut: Ar-Risalah, cet 11, 2001.

Daradjat, Zakiah. Islam Untuk Disiplin Ilmu Pendidikan. Jakarta: Bulan Ibntang, 1987.

Departemen Agama RI. Al-Qur'an dan Terjamahnya. Depok: PT Sabiq, 2009.

Fadjar, Abdul Malik. Holistika Pemikiran Pendidikan, edit. Ahmad Barizi. Jakarta: RajaGrafindo Persada, 2005.

Ibn Battal, 'Ali ibn Khalf. Syarh al-Bukhari, tahqiq Abu Tamim Yasir ibn Ibrahim,. Riyad: Maktabah ar-Rusyd, cet. 2, 2003.

Langgulung, Hasan. Beberapa Pemikiran tentang Pendidikan Islam. Bandung: Al-Ma'arif, 1980.

Muslim. Sahih Muslim, tarqim wa tartib Muhammad Fuad 'Abd al-Baqi. Kairo: Dar Ibn Hazm, 2010.

Qasim, Hamzah Muhammad. Manar al-Qari Syarh Mukhtasar Sahih al-Bukhari, muraja'ah al-Arna'ut. Damaskus: Maktabah Dar al-Bayan, 1990.

Tafsir, Ahmad. Ilmu Pendidikan dalam Perspektif Islam. Bandung: PT Remaja Rosdakarya, 1992. 2013. . Ilmu Pendidikan Islam. Bandung: PT Remaja Rosdakarya, cet. 2,

Tim Penyusun Departemen Pendidikan Nasional. Kamus Besar Bahasa Indonesia. Jakarta: Gramedia Pustaka Utama, cet. 4, 2008.

Uhbiyati, Nur. Ilmu Pendidikan Islam. Bandung: Pustaka Setia, 1998 